\title{
MASCULINIDADE APREENDIDA NA \\ INFÂNCIA/ADOLESCÊNCIA DE HOMENS EM \\ PROCESSO CRIMINAL POR VIOLÊNCIA CONJUGAL
}

\author{
MASCULINITY SEIZED IN \\ CHILDHOOD/ADOLESCENCE OF MEN IN \\ CRIMINAL PROCEEDINGS FOR MARITAL VIOLENCE
}

\section{LA MASCULINIDAD INCAUTADA DE LA INFANCIA/ADOLESCENCIA DE LOS HOMBRES EN LOS PROCESOS PENALES POR VIOLENCIA CONYUGAL}

\author{
Andrey Ferreira da Silva ${ }^{1}$ \\ Fernanda Matheus Estrela ${ }^{2}$ \\ Júlia Renata Fernandes Magalhães ${ }^{3}$ \\ Álvaro Pereira ${ }^{4}$ \\ Nadirlene Pereira Gomes ${ }^{5}$ \\ Milena Arão da Silva Oliveira ${ }^{6}$ \\ Vera Lúcia de Azevedo Lima
}

Como citar este artigo: Silva AF, Estrela FM, Magalhães JRF, Pereira A, Gomes NP, Oliveira MAS, et al. Masculinidade apreendida na infância/adolescência de homens em processo criminal por violência conjugal. Rev baiana enferm. 2021;35:e43184.

Objetivo: compreender os elementos constitutivos da masculinidade que permearam a infância e/ou adolescência de homens em processo criminal por violência conjugal. Método: estudo qualitativo utilizando-se o referencial metodológico História Oral de Vida. Foram realizadas entrevistas com 13 homens em processo criminal por violência conjugal vinculados à $2^{\underline{a}}$ Vara de Justiça pela Paz em Casa do município de Salvador, Bahia, Brasil. Os dados foram interpretados à luz do referencial teórico sobre masculinidade. Resultados: a infância/adolescência dos homens foi permeada por constructos da masculinidade, na sua maioria introjetados pela figura paterna. São eles: o distanciamento de brincadeiras femininas, embotamento afetivo, infidelidade, provisão familiar e domínio e violência intrafamiliar. Considerações Finais: mesmo não sendo possível afirmar que esses padrões tenham influenciado no desenvolvimento da agressividade, infere-se que a observação, o incentivo, a imposição e o convívio com os elementos da masculinidade tenham contribuído para delinear o caráter dos participantes e refletido em suas condutas na vida adulta.

Descritores: Saúde do Homem. Masculinidades. Violência de Gênero. Interação Pais-Filho. Comportamento Social.

\footnotetext{
Enfermeiro. Doutor em Enfermagem. Docente da Faculdade Estácio de Alagoas. Maceió, Alagoas, Brasil. silva.andrey199|@hotmail.com. http://orcid.org/00000002-1038-7443.

2 Enfermeira. Doutora em Enfermagem. Docente da Universidade Estadual de Feira de Santana. Feira de Santana, Bahia, Brasil. http://orcid.org/0000-000 I-750 I -6 I 87. Enfermeira. Enfermeira assistencial da Unidade de Pronto Atendimento Guanambi. Coordenadora da Unidade de Internação de Alta Complexidade em Oncologia. Guanambi, Bahia, Brasil. http://orcid.org/0000-0003-063I-2374.

Enfermeiro. Doutor em Enfermagem. Docente da Universidade Federal da Bahia. Salvador, Bahia, Brasil. http://orcid.org/0000-0003-1899-7374

Enfermeira. Doutora em Enfermagem. Docente da Universidade Federal da Bahia. Salvador, Bahia, Brasil. http://orcid.org/0000-0002-6043-3997.

Enfermeira. Universidade Federal da Bahia. Salvador, Bahia, Brasil. http://orcid.org/0000-0003-3933-99|X.

Enfermeira. Docente da Universidade Federal do Pará. Belém, Pará, Brasil. http://orcid.org/0000-0003-0094-4530.
} 
Objective: to understand the constitutive elements of masculinity that permeated the childhood and/or adolescence of men in criminal proceedings for marital violence. Method: qualitative study using the methodological framework Oral History of Life. Interviews were conducted with 13 men in criminal proceedings for marital violence linked to the $2^{\text {nd }}$ Court of Justice for Home Peace in the municipality of Salvador, Bahia, Brazil. The data were interpreted in the light of the theoretical framework on masculinity. Results: men's childhood/adolescence was permeated by masculinity constructs, mostly influenced by the father figure. They are: the distancing of female games, affective dullness, infidelity, family provision and dominance and family violence. Final Considerations: even though it is not possible to affirm that these patterns have influenced the development of aggressiveness, it is inferable that observation, encouragement, imposition and conviviality with the elements of masculinity have contributed to delineate the character of the participants and reflected in their conducts in adulthood.

\section{Descriptors: Men's Health. Masculinities. Gender Violence. Parent-Child Interaction. Social Behaviour.}

Objetivo: comprender los elementos constitutivos de la masculinidad que impregnaron la infancia y/o adolescencia de los hombres en los procesos penales por violencia conyugal. Método: estudio cualitativo utilizando el marco metodológico Historia Oral de la Vida. Se realizaron entrevistas a 13 bombres en procesos penales por violencia conyugal vinculados a la $2^{a}$ Corte de Justicia por la Paz en la Casa del municipio de Salvador, Bahí, Brasil. Los datos fueron interpretados a la luz del marco teórico sobre la masculinidad. Resultados: la infancia/adolescencia de los hombres estuvo impregnada de construcciones de masculinidad, en su mayoría introyectadas por la figura paterna. Son ellos: el distanciamiento de los juegos femeninos, la atonía afectiva, la infidelidad, la provisión y dominación familiar y la violencia familiar. Consideraciones finales: aunque no es posible afirmar que estos patrones hayan influido en el desarrollo de la agresividad, es inferible que la observación, el estímulo, la imposición y la convivencia con los elementos de la masculinidad han contribuido a delinear el carácter de los participantes y se han reflejado en sus conductas en la edad adulta.

Descriptores: Salud del Hombre. Masculinidades. Violencia de Género. Interacción Padre-Hijo. Comportamiento Social.

\section{Introdução}

O ser homem em nossa sociedade se alicerça na desigualdade de gênero, uma vez que alguns ensinamentos atribuídos à figura masculina, quando utilizados de forma destrutiva e fundadas no patriarcado, trazem danos para toda a sociedade, inclusive para os próprios homens ${ }^{(1)}$. Tal contexto remete para a necessidade de reconstrução desse modelo hegemônico, que vem sendo apreendido ao longo das gerações e resultando em problemas de saúde e sociais, como os homicídios, os acidentes de trânsito e a violência doméstica e conjugal.

Situada no campo das relações de gênero, a masculinidade pode ser compreendida como um conjunto de atributos e funções que se esperam dos homens e que servem de orientação para a construção de sua identidade. Esses constructos são incorporados no modo de ser masculino mediante as experiências acumuladas ao longo de sua história, principalmente por meio das relações sociais. Durante a infância e a adolescência, esse processo ocorre por meio da apropriação daquilo que ele vivencia em seu cotidiano, principalmente em seu contexto familiar, tendo os pais como as figuras de referência que influenciam em sua formação, em especial, a figura paterna ${ }^{(2)}$.

Quando essa criança e adolescente estão inseridos em um ambiente doméstico que se configura como violento, podem incorporar ao seu modo de ser os comportamentos patriarcais, havendo assim a reprodução dessas atitudes quando adultos. Isso é corroborado em estudo brasileiro que afirma a tendência de naturalizar e reproduzir esses modelos nas relações conjugais, tornando os homens mais violentos do que quando não expostos ao agravo ${ }^{(3)}$.

Todo esse contexto em que os homens são educados, inclusive em ambientes violentos, revelam a alta incidência de casos de violência. No Brasil, pesquisa realizada com 1.102 mulheres revela que uma em cada cinco brasileiras já vivenciou algum tipo de violência doméstica ou familiar, na maioria das vezes praticada pelo 
cônjuge $^{(4)}$. Mesmo em países desenvolvidos como Estados Unidos da América (EUA) e Inglaterra, os números da violência conjugal são elevados, tendo os parceiros íntimos como os principais perpetradores ${ }^{(5)}$. Essas práticas criminosas, nas quais se insere a violência conjugal, ancoram-se na educação desigual de gênero, que reforça o poder e a dominação masculina, enfatizando a subserviência feminina ${ }^{(3)}$.

Para a prevenção da violência doméstica e conjugal, se fazem necessárias adoção de estratégias que possibilitem a criação de meninos e meninas pautando-se em atributos e papéis mais simétricos, propiciando a reconstrução do modelo de masculinidade hegemônico. Dessa forma, adotou-se como questão de pesquisa: Quais os elementos constitutivos da masculinidade que permearam a infância e/ou adolescência de homens em processo criminal por violência conjugal devido às relações familiares? Nesse sentido, o estudo apresenta o seguinte objetivo: compreender os elementos constitutivos da masculinidade que permearam a infância e/ou adolescência de homens em processo criminal por violência conjugal com base nas relações familiares.

\section{Método}

Trata-se de estudo de abordagem qualitativa, que utilizou o referencial teórico das masculinidades.

Os participantes da pesquisa foram 13 homens vinculados à $2^{\underline{a}}$ Vara de Justiça pela Paz em Casa, situada no município de Salvador, Bahia, Brasil. A seleção dos participantes deu-se de forma intencional, respeitando os critérios de inclusão: estar respondendo a processo criminal por violência conjugal na referida Vara e estar em condições psicoemocionais visivelmente estáveis no momento da entrevista. Destaca-se que tal avaliação ocorreu após a observação de uma profissional de psicologia da própria Vara de Justiça, que indicou os participantes para a realização das entrevistas. Foram excluídos do estudo os homens que não compareceram às entrevistas após dois agendamentos consecutivos.
O processo de aproximação com os participantes deu-se após a inserção do pesquisador principal no Grupo Reflexivo de Homens (GRH), no qual os homens participavam por determinação judicial. Os encontros do GRH ocorrem semanalmente, com duração média de duas horas, e são mediados por uma equipe multidisciplinar composta por profissionais e estudantes da área da saúde e do direito. Esses encontros possibilitaram maior vínculo com os possíveis colaboradores. Vale destacar que não houve conflitos de interesse, visto que tal aproximação é metodologicamente preconizada com vistas ao aprofundamento das entrevistas em História Oral de Vida (HOV) ${ }^{(6)}$.

Após o término do ciclo de encontros, os participantes foram contactados por via telefônica e convidados a participar do estudo, tendo sido esclarecidos os objetivos do estudo, o direito de participar ou não da pesquisa, bem como de desistir a qualquer momento, a garantia do anonimato e a confidencialidade das informações. O anonimato dos participantes foi mantido com a substituição dos nomes pela codificação alfanumérica (H1, H2... H13). Foram observados os preceitos éticos contidos nas Resoluções $\mathrm{n}^{\mathrm{o}}$ 466/12 e no 510/2016, ambas do Conselho Nacional de Saúde (CNS). Após anuência, os participantes assinaram o Termo de Consentimento Livre e Esclarecido (TCLE). A pesquisa foi realizada mediante aprovação do Comitê de Ética em Pesquisa (CEP) da Universidade Federal da Bahia, sob Parecer no 877.905, Certificado de Apresentação de Apreciação Ética (CAAE) 31286414.2.0000.5531. O estudo seguiu os critérios do Consolidated Criteria for Reporting Qualitative Research (COREQ).

Foram realizadas 13 entrevistas. A coleta de dados foi realizada pelo pesquisador principal e aconteceu entre os meses de abril e julho de 2018, em horário e local previamente escolhidos pelos participantes, tais como suas residências ou espaços abertos que possibilitassem a ocorrência das narrativas. Por meio de entrevista semiestruturada, os participantes foram indagados acerca dos seus aspectos sociodemográficos (idade, religião, raça/cor, escolaridade, renda familiar) 
e responderam à seguinte questão norteadora: Fale-me que elementos da masculinidade permearam a sua infância e/ou adolescência.

As entrevistas foram realizadas pelo pesquisador principal e tiveram duração média de duas horas e trinta minutos. Foram gravadas, transcritas, transcriadas (organização lógica do texto) e textualizadas (organização do discurso na primeira pessoa do singular, sendo excluídos os elementos desnecessários), conforme preconizado pelo referencial metodológico da $\mathrm{HOV}^{(6)}$. Cabe ressaltar que, por valorizar as narrativas emanadas no processo de coleta de dados, esse referencial permite a delimitação do número de participantes com base na saturação do conteúdo das falas, não havendo a necessidade de um elevado número de pessoas para integrar o estudo. Ao final do processo de organização do corpus textual, este foi disponibilizado na íntegra para leitura e validação por parte dos participantes da pesquisa, os quais assinaram a carta de cessão de direitos, autorizando o uso das entrevistas para análise.

Assim, após leitura exaustiva, exploração do material e categorização dos dados, estes foram interpretados à luz do referencial de Masculinidade Hegemônica ${ }^{(1)}$. Vale salientar que o processo de categorização foi propiciado pelo software NVIVO ${ }^{\circledR} 11$, que favorece a sistematização de dados qualitativos. Cabe destacar que a análise de dados foi realizada por pares, evitando dessa forma os vieses de interpretação. Emergiram seis categorias, a saber: distanciamento de brincadeiras femininas, embotamento afetivo, impulsividade, infidelidade, provisão da família e domínio e violência intrafamiliar.

\section{Resultados}

Os 13 participantes da pesquisa apresentavam idade entre 27 e 54 anos. A maioria autodeclarou-se negro (11), religioso, católico e evangélico (12), com nível superior (6) e com renda familiar de dois a dez salários mínimos mensais (8).

Os elementos constitutivos da masculinidade que permearam a infância e/ou adolescência de homens em processo criminal por violência conjugal foram apresentados nas seguintes categorias:

\section{Distanciamento de brincadeiras femininas}

Como constructo de masculinidade, a historicidade dos participantes da pesquisa foi permeada pelo reforço às brincadeiras estereotipadas de meninos. Ficou clara a preocupação pela parte paterna em assegurar o filho-homem, por meio do distanciamento da criança às brincadeiras do universo feminino.

\begin{abstract}
Meu pai sempre foi muito conservador em relação à masculinidade por conta do meu avô que nunca aceitou determinadas situações vindas do bomem, como brincar de boneca, de casinha, essas coisas. Durante toda a minha infância, eles não me deixavam brincar com minhas irmãs e primas. (H01).
\end{abstract}

Meu pai sempre me dizia que eu deveria brincar de jogar futebol e videogame [...] não me deixava brincar com as meninas, até porque elas brincavam de boneca e de casinha e isso não era brincadeira de homem. (H06).

\section{Embotamento afetivo}

A oralidade de homens em processo criminal por violência conjugal desvelou como características masculinas presentes no seu cotidiano infantil traços de personalidade introspectiva, expressos pela não externalização de emoções e limitada interação social. Estas, que configuram embotamento afetivo, lhes foram ensinadas como atributo inerente ao ser homem.

\footnotetext{
Meu pai é um homem fechado, dificilmente ele interagia com os membros da família, parecia que gostava de ficar só [...] durante minha infância, nunca vi meu pai chorar por nada, sempre dizia que bomem não chora. (H07).

Quando eu era criança, meu pai me dizia que é melhor viver sozinho do que mal acompanhado [...] Ele não chorava, seguia em frente [...] me ensinou que isso é ser bomem! (H05).
}

\section{Impulsividade}

Atitudes impulsivas, sem a mensuração de suas repercussões nas relações familiares e sociais, foi apontada enquanto elemento constituinte da masculinidade dos homens. Este comportamento também foi experienciado ao longo de suas vidas, conforme ilustram as falas: 
Ele [pai] era tão impulsivo que diante de qualquer conflito, seja familiar ou não, já estava com arma em punbo [...] nunca pensava nas consequências disso para ele e para a nossa família. (H13).

Meu pai sempre foi muito afoito e impulsivo, agia sem pensar, sem refletir. Tomava decisões de forma precipitada e depois sofria com as consequências. (H02).

\section{Infidelidade}

A infidelidade masculina também foi revelada enquanto constituinte do constructo de masculinidade dos participantes da pesquisa. Esta foi testemunhada mediante a observação do comportamento paterno em situações de traição marital, marcada inclusive pela descoberta de uma nova constituição familiar.

Quando eu era criança, meu pai arranjou uma amante [...] chegou até a constituir família e isso ficou muito marcado em minha memória. Eu acho que é normal! (H03).

Meu pai tinha outros relacionamentos, outros filhos, inclusive com as mesmas idades que as nossas. Todo mundo sabia disso e até minha mãe aceitava essa situação. (H13).

\section{Provisão da família}

Ao longo da vida, os entrevistados conviveram com a supervalorização do trabalho pela figura masculina, condição que possibilita a provisão familiar. Essa responsabilidade, que lhes foi introjetada desde a infância, é percebida como elemento constitutivo do ser homem.

Ele [pai] me dizia que o trabalbo dignifica o bomem. Pensava 24 horas em trabalho, pois não gostava que nada faltasse dentro de casa [...] dizia que isso era responsabilidade do bomem! (H01).

Meu avô sempre nos ensinou a trabalhar duro para sustentar a casa, pagar as contas, prover os alimentos. (H04).

\section{Domínio e violência intrafamiliar}

As narrativas revelaram uma história de vida permeada pelo modelo autoritário do pai enquanto chefe de família, que não permitia ser questionado nem contrariado em suas ordens. A relação de poder presente na relação familiar desponta o sentido da dominação masculina, que autoriza o homem a ter condutas agressivas e violentas para com sua esposa e filhos, comportamentos experienciados pelos entrevistados na sua infância e adolescência.

\begin{abstract}
Fui criado por meu pai dessa forma: o homem é o chefe da familia, quem deve guiar a casa, impor as regras [...] Meu pai obrigava que as coisas fossem apenas do jeito dele e ninguém podia se contrapor. Ele proibiu de falar para minha mãe que ele era agressivo conosco [filhos], como eu contei, ele me espancou. Ele já jogou as panelas em minha mãe porque ela não cozinhou o que ele pediu. Ela queria se separar dele, mas ele não aceitava. (H08).
\end{abstract}

As coisas tinham que ser do jeito que meu pai queria: o que ele falava era lei e a ordem tinha que ser cumprida e ninguém podia falar nada. Tudo que eu vivi na minha infância e adolescência com certeza foi violência. Meu pai me agredia de pau, de pedra, me algemava. Chegava até ao extremo de colocar eu e meus irmãos sentados no sofá e atirava por cima das nossas cabeças. Minha mãe nunca pensou em se separar porque tinha medo dele. (H13).

\section{Discussão}

O estudo aponta que um dos elementos constituintes da masculinidade que permeou a infância e/ou adolescência de homens em processo criminal por violência conjugal encontra-se imbricado no engajamento paterno para o distanciamento dos meninos das brincadeiras infantis, consideradas intrínsecas ao feminino, como bonecas e casinha. Essa tendência é compartilhada em estudo nacional que afirma que as crianças e adolescentes são estimuladas socialmente a experienciar atividades lúdicas que favoreçam o constructo dos padrões de gênero do homem e da mulher ${ }^{(7)}$.

No caso de meninos, as condutas frequentemente adotadas pelos pais no processo de criação infantil tendem ao afastamento de brincadeiras consideradas femininas, o que configura ação de controle no desenvolvimento da masculinidade. Essa ação muitas vezes encontra-se associada a uma preocupação paterna em garantir que o filho não "se torne" homossexual. Apesar disso, estudo norte-americano destaca que a orientação sexual independe do controle dos pais, mesmo que estes utilizem de uma criação pautada no binarismo de gênero ${ }^{(8)}$.

Outro atributo constituinte da masculinidade relaciona-se à figura do homem "provedor". Tal elemento também se mostrou presente no contexto familiar dos participantes, de modo que 
as suas representações masculinas de referência apropriaram-se do posto de "chefe da casa", condição que os colocaram na função de suprir as necessidades financeiras da família. Em estudo realizado na Espanha, foi apontado essa legitimação social masculina de prover financeiramente seus filhos e esposa, demostrando ser este um valor importante na sociedade ${ }^{(9)}$. Esse atributo é introjetado no imaginário masculino na infância e na adolescência. Isso o faz sentir-se valorizado enquanto homem trabalhador, que sustenta financeiramente sua família, porém contribui para que muitos homens não estejam presentes de forma ativa na criação das crianças, denotando afastamento familiar.

A valorização masculina sob a condição de provedor denota no homem uma conjuntura de poder nas relações, acreditando que, por suprir as necessidades financeiras e alimentares da casa, deve ser respeitado, podendo, inclusive, cometer traição marital; elemento presente em vários contextos familiares e que permeou a infância dos participantes. Nessa perspectiva, ser infiel, significa virilidade e denota a condição de ser másculo, vigoroso, potente. Possui também um significado associado à sexualidade, o qual ancora-se ao desejo sexual ${ }^{(10)}$.

Concernente a isso, a história de vida dos homens encontra-se marcada por presenciar a infidelidade paterna, inclusive com a constituição de outros núcleos familiares, por meio do estabelecimento de relações poligâmicas, mesmo com o conhecimento do cônjuge. Tal conduta é percebida socialmente como um comportamento inerente ao masculino, sendo a traição marital popularmente considerada de maior propensão para os homens ${ }^{(10)}$. Estudo nacional demonstrou que de 106 homens entrevistados, 75\% já haviam traído suas companheiras, relatando, inclusive, a aceitação destas a essa situação ${ }^{(11)}$.

Conforme as narrativas, o distanciamento masculino de condutas tidas como femininas também está relacionado à não expressão das emoções. Estudo nacional revela que, desde os momentos iniciais da infância, é evidente a existência de pressão social para que os meninos não chorem, afixando no imaginário masculino que o lacrimejar denota descontrole, covardia e $\operatorname{medo}^{(12)}$.

Vale alertar, ainda, que ao ter suas emoções tolhidas, o homem passa a agregar à sua personalidade traços introspectivos, o que também limita a sua interação social, levando-o, muitas vezes, a suprimir suas emoções, o que tende a repercutir de forma negativa em sua saúde mental e física. Corroborando tais achados, estudo realizado na Índia revela que a ausência de diálogo masculino nas relações familiares e conjugais vem sustentando a crença do homem contemporâneo introspectivo ${ }^{(13)}$, elemento do ser homem, que também permeou o contexto familiar dos participantes. Nesses casos, as narrativas revelam ações não comedidas e sem mensuração das suas repercussões, tanto individuais quanto coletivas, a exemplo do uso de armas de fogo em situações de conflitos familiares. Essa ideologia determina que os homens têm que defender suas reputações, suas famílias e propriedades contra ameaças e insultos. Assim, espera-se socialmente que eles estejam dispostos e sejam capazes de envolver-se em agressão física quando considerarem haver necessidade ${ }^{(14)}$.

Essa superioridade masculina também é evidenciada no cenário familiar, visto o status de chefe da casa que confere ao homem a autonomia para ditar suas decisões frente aos demais membros da família. Estudos internacionais revelam a autoridade masculina sobre a família, sendo o homem o detentor do poder, inclusive impedindo que os filhos e a esposa expressem suas opiniões ${ }^{(15)}$.

Essa característica de chefe da família fez-se presente na infância e adolescência dos entrevistados e encontra-se atrelada ao modelo autoritário de masculinidade. Para além do status de chefe da família, os homens impõem o respeito familiar, usando, inclusive, da agressividade, conforme revela estudo espanhol ${ }^{(16)}$. A relação de poder presente no seio familiar desponta o sentido da dominação masculina sobre as crianças/adolescentes, com a adoção de condutas agressivas, a exemplo do uso de pau e pedra para cometer a violência física ou psicológica, o que repercute na concepção de que tais 
atitudes fazem parte dos processos educacionais, levando à reprodução. Corroborando essas atitudes, estudos realizados na África e na América do Sul identificaram que a figura paterna aparece dentre os principais agressores no âmbito familiar ${ }^{(17-18)}$.

As narrativas desvelam ainda que a imposição do poder masculino extrapola a relação adulto-criança, sendo evidente também no relacionamento conjugal. Os participantes revelaram ter testemunhado cenas de violência praticada pelo pai contra a mãe, ressaltando o não cumprimento do desejo masculino como precipitador da agressão. Estudo mexicano releva que um dos elementos que precipitam e intensificam a violência nas relações familiares é justamente a não realização de tarefas domésticas ${ }^{(19)}$. Em um cenário de dominação masculina não existe espaço para tomada de decisão feminina, até mesmo em relação ao desejo de permanecer ou não na relação conjugal, conforme expressam as narrativas. Tal contexto evidencia a condição de subalternidade feminina no tocante às deliberações e aceitação de condutas corretivas ${ }^{(3)}$. Esse constructo, favorecedor da objetificação feminina, acaba inserindo a violência conjugal no contexto familiar. Vivência essa relatada pelos participantes da pesquisa.

Embora o estudo limite-se por não investigar se os elementos constitutivos da masculinidade que permearam a infância e/ou adolescência de homens em processo criminal por violência conjugal foram reproduzidos na vida adulta, infere-se que, por constituírem o modelo dominante, esses elementos tenham sido assumidos como influência para comportamentos pautados no poder e na dominação. Outra limitação situa-se no fato de que os referidos elementos poderão se configurar de modos distintos por outros homens que convivam em comunidades com costumes e criações sociais divergentes.

Apresenta-se como limitação do estudo trabalhar aspectos históricos e subjetivos dos entrevistados, além da regionalidade da coleta e a unilateralidade da questão com base no ponto de vista masculino.

\section{Considerações Finais}

As narrativas revelam que a infância/adolescência de homens em processo criminal por violência conjugal foi permeada por constructos da masculinidade, na sua maioria introjetados pela figura paterna. São eles: o distanciamento de brincadeiras femininas, embotamento afetivo, impulsividade, infidelidade, provisão familiar e domínio e violência intrafamiliar.

Mesmo não sendo possível afirmar que esses padrões tenham influenciado no desenvolvimento da agressividade, infere-se que a observação, o incentivo, a imposição e o convívio com os elementos da masculinidade tenham contribuído para delinear o caráter dos participantes e refletido em suas condutas na vida adulta, uma vez que diversos estudos apontam que a formação do indivíduo é direcionada com base nas suas experiências quando crianças e adolescentes.

Tendo em vista que a violência conjugal é permeada fundamentalmente por elementos hegemônicos de masculinidade que sustentam a supremacia dos homens, colocando-os em risco para si mesmo e para outros, é salutar a necessidade de espaços de valorização da educação baseada na simétricas entre os gêneros, que possibilite a reconstrução da masculinidade, substituindo-a por um modelo de formação do novo homem.

\section{Colaborações:}

1 - concepção, projeto, análise e interpretação dos dados: Andrey Ferreira da Silva, Fernanda Matheus Estrela, Júlia Renata Fernandes Magalhães, Álvaro Pereira, Nadirlene Pereira Gomes, Milena Arão da Silva Oliveira e Vera Lúcia de Azevedo Lima;

2 - redação do artigo e revisão crítica relevante do conteúdo intelectual: Andrey Ferreira da Silva, Fernanda Matheus Estrela, Júlia Renata Fernandes Magalhães, Álvaro Pereira, Nadirlene Pereira Gomes, Milena Arão da Silva Oliveira e Vera Lúcia de Azevedo Lima; 
3 - aprovação final da versão a ser publicada: Andrey Ferreira da Silva, Fernanda Matheus Estrela, Júlia Renata Fernandes Magalhães, Álvaro Pereira, Nadirlene Pereira Gomes, Milena Arão da Silva Oliveira e Vera Lúcia de Azevedo Lima.

\section{Referências}

1. Connell RW, Messerschmidt JW. Masculinidade hegemônica: repensando o conceito. Rev Estud Fem. 2013;21(1):241-82. DOI: 10.1590/ S0104-026X2013000100014

2. Hedlin M, Åberg M, Johansson C. Fun guy and possible perpetrator: an interview study of how men are positioned within early childhood education and care. Educ Inq. 2019;10(2):95-115. DOI: $10.1080 / 20004508.2018 .1492844$

3. Paixão GPN, Pereira A, Gomes NP, Sousa AR, Estrela FM, Silva Filho URP, et al. Naturalization, reciprocity and marks of marital violence: male defendants' perceptions. Rev Bras Enferm. 2018;71(1):178-84. DOI: 10.1590/0034-7167-2016-0475

4. Sousa AR, Estrela FM, Silva AF, Magalhães JRF, Oliveira MADS, Loureiro AKNS, et al. Violência conjugal e prática assistencial por níveis de atenção à saúde: discurso de enfermeiras. Cogitare Enferm. 2021;26:e7403. DOI: http:// dx.doi.org/10.5380/ce.v26i0.74083

5. Niolon PH, Kearns M, Dills J, Rambo K, Irving S, Armstead TL, et al. Preventing Intimate Partner Violence Across the Lifespan: A Technical Package of Programs, Policies, and Practices [Internet]. Atlanta, Georgia: National Center for Injury Prevention and Control, Centers for Disease Control and Prevention; 2017 [cited 2020 May 14]. Available from: https://www.cdc.gov/ violenceprevention/pdf/ipv-technicalpackages. pdf

6. Meihy JCFB, Holanda F. História oral: como fazer, como pensar. 2a ed. São Paulo: Contexto; 2014.

7. Pessoa LF, Ramos DO, Seidl-de-Moura ML, Silva LO. A valorização da obediência infantil como meta de socialização em diferentes configurações familiares. Psicol Clínica. 2018;30(1):147-63. DOI: 10.33208/pc1980-5438v 0030n01a08

8. Mitrani VB, De Santis JP, McCabe BE, Deleon DA, Gattamorta KA, Leblanc NM.
The Impact of Parental Reaction to Sexual Orientation on Depressive Symptoms and Sexual Risk Behavior Among Hispanic Men Who Have Sex with Men. Arch Psychiatr Nurs. 2017;31(4):352-8. DOI: 10.1016/j.apnu.2017.04.004

9. Affleck W, Thamotharampillai U, Jeyakumar J, Whitley R. "If One Does Not Fulfil His Duties, He Must Not Be a Man": Masculinity, Mental Health and Resilience Amongst Sri Lankan Tamil Refugee Men in Canada. Cult Med Psychiatry. 2018;42(4):840-61. DOI: 10.1007/s11013-018-9592

10. Ledikwe JH, Ramabu NM, Spees LP, Barnhart S, Ntsuape C, Semo B, et al. Early resumption of sexual activity following voluntary medical male circumcision in Botswana: A qualitative study. PLoS One. 2017;12(11):e0186831. DOI: 10.1371/ journal.pone.0186831

11. Scheeren P, Apellániz IAM, Wagner A. Infidelidade Conjugal: A Experiência de Homens e Mulheres. Temas psicol. 2018;26(1):355-69. DOI: 10.9788/ TP2018.1-14Pt

12. Rungreangkulkij S, Kotnara I, Kittiwatanapaisan W, Arunpongpaisal S. Loss of Control: Experiences of Depression in Thai Men. Walailak J Sci Technol. 2018;16(4):265-74. DOI: https://doi.org/10.48048/ wjst.2019.3584

13. Schuler SR, Lenzi R, Badal SH, Nazneen S. Men's perspectives on women's empowerment and intimate partner violence in rural Bangladesh. Cult Health Sex. 2018 Jan;20(1):113-27. DOI: 10.1080/13691058.2017.1332391

14. Sikweyiya Y, Addo-Lartey AA, Alangea DO, Dako-Gyeke P, Chirwa ED, Coker-Appiah D, et al. Patriarchy and gender-inequitable attitudes as drivers of intimate partner violence against women in the central region of Ghana. BMC Public Health. 2020;20(1):682. DOI: 10.1186/ s12889-020-08825-Z

15. Hadas M. The Tricky 'True Object': Bourdieu's Masculine Domination and Historicity. Masculinities Soc Chang. 2016;5(3):210. DOI: http://dx.doi.org/10.17583/mcs.2016.2029

16. Delgado ADV, Viejo CM. Masculinities and Emotional Deficit: Linkages between Masculine Gender Pattern and Lack of Emotional Skills in Men who Mistreat Women in Intimacy. Masculinities Soc Chang. 2017;6(2):166. DOI: 10.17583/mcs.2017.2589

17. Fundação Abrinq pelos Direitos da Criança e do Adolescente. A criança e o adolescente nos 
ODS: Marco zero dos principais indicadores brasileiros [Internet]. São Paulo: 2017 [cited 2020 Mar 28]. Available from: https://observatoriocrianca. org.br/system/library_items/files/000/000/002/ original/Publica\%C3\% A 7\%C3\% A 3O_A_ Crian\%C3\%A7a_e_O_Adolescente_nos_ODS. pdf?1510343062

18. Sharma V, Leight J, Verani F, Tewolde S, Deyessa N. Effectiveness of a culturally appropriate intervention to prevent intimate partner violence and HIV transmission among men, women, and couples in rural
Ethiopia: Findings from a cluster-randomized controlled trial. PLoS Med. 2020;17(8):e1003274. DOI: $10.1371 /$ journal.pmed.1003274

19. Juan TF, Madan LF. Bidirectional Violence among Male and Female University Students: Comparison of Observations and Results between Two Countries. Masculinities Soc Chang. 2018;7(3):279-312. DOI: 10.17583/mcs.2018.3499

Recebido: 21 de janeiro de 2021

Aprovado: 7 de junho de 2021

Publicado: 22 de julho de 2021

A Revista Baiana de Enfermagem utiliza a Licença Creative Commons - Atribuição-NãoComercial 4.0 Internacional. https://creativecommons.org/licenses/by-nc/4.0/

Este artigo é de acesso aberto distribuído sob os termos da Licença Creative Commons (CC BY-NC). Esta licença permite que outros remixem, adaptem e criem a partir do seu trabalho para fins não comerciais. Embora os novos trabalhos tenham de lhe atribuir o devido crédito e não possam ser usados para fins comerciais, os usuários não têm de licenciar esses trabalhos derivados sob os mesmos termos. 